\title{
Discussion to the paper by W. K. Eltringham, M. E. Jenny and A. P. Morgan
}

HofFBRAND. Have you looked at the circulatory changes produced by prolonged infusion of moderately high doses of noradrenaline, and does the animal show any evidence of cardiac failure? Could the changes be secondary to circulatory pathology?

ELTRINGHAM. We did not record the circulatory effects but others have. At high dose levels, well in excess of those used in this series, noradrenaline will produce death of animals in shock with a progressively falling blood volume, deterioration of myocardial function and acidosis. Schenk \& Moss (1966) have studied this problem carefully at dose levels between 1 and $4 \mu \mathrm{g} / \mathrm{kg} / \mathrm{min}$. At the lower dose-level the cardiovascular effects are slight. Our animals, apart from some initial tachypnoea and tachycardia were undisturbed by the infusion and there was no significant haemoconcentration, and further, lactate levels and $\mathrm{pH}$ were normal throughout.

The fatty changes are undoubtedly due to the mobilization of lipid and high FFA levels in the blood. However, other changes such as the cell necrosis that has been described by others and enzyme changes suggestive of cell damage, may be related to circulatory pathology. Their cause is unknown in fact. They do not appear to be related to the amount of lipid deposition.
WALDER. Is the fat in the liver extravascular?

ELTRINGHAM. It is intracellular and may accumulate $\frac{\vec{\sigma}}{\vec{\phi}}$ in the lungs over a long period as in classical fat em- $\unrhd$ bolism. We found no extracellular lipid in liver or lungs. क

Chamberlain. We (Allison, Prowse \& Chamberlain, $\vec{\circ}$ 1967; Allison, Hinton \& Chamberlain, 1968) found in a variety of shock states-burns, myocardial infarction and $\overrightarrow{\vec{\omega}}$ surgical operations - a pattern of high FFA as described $\stackrel{\sigma}{\sigma}$ in noradrenaline-infused dogs, and failure of insulin- $\vec{D}$ response to a glucose load, which we attributed to high 3 levels of endogenous adrenaline. The more severe the injury, the lower the blood pressure and the worse the of state of shock, the more marked was the failure of insulin ir production.

\section{References}

Allison, S.P., Hinton, P. \& Chamberlain, M.J. (1968) 음 Intravenous glucose tolerance, insulin, and free fatty acid levels in burned patients. Lancet, ii, 1113.

Allison, S.P., Prowse, K. \& Chamberlain, M.J. (1967) Failure of insulin response to glucose load during operation and after myocardial infarction. Lancet, $\mathbf{i}, 478$.

Schenk, E.A. \& Moss, A.J. (1966) Cardiovascular effects of sustained norepinephrine infusions. II. Morpholog of Circulat. Res. 18, 605. 